\title{
Maternal and familial correlates of anthropometric typologies in the nutrition transition of Colombia, 2000-2010
}

Diana C Parra ${ }^{1,2, *}$, Luis F Gomez ${ }^{3}$, Lora lannotti ${ }^{4}$, Debra Haire-Joshu ${ }^{5}$, Anne K Sebert Kuhlmann ${ }^{6}$ and Ross C Brownson ${ }^{7,8}$

${ }^{1}$ Program of Physical Therapy, Washington University in St. Louis School of Medicine, 4444 Forest Park Avenue, St. Louis, MO 63108, USA: ${ }^{2}$ Department of Surgery, Rosario University, Bogota, Colombia: ${ }^{3}$ Facultad de Medicina, Pontificia Universidad Javeriana, Bogotá, Colombia: ${ }^{4}$ Brown School, Washington University in St. Louis, St. Louis, MO, USA: ${ }^{5}$ Center For Diabetes Translation Research, Brown School, Washington University in St. Louis, St. Louis, MO, USA: ${ }^{6}$ College for Public Health \& Social Justice, Saint Louis University, St. Louis, MO, USA: ${ }^{7}$ Prevention Research Center in St. Louis, Brown School, Washington University in St. Louis, St. Louis, MO, USA: ${ }^{8}$ Division of Public Health Sciences and Alvin J. Siteman Cancer Center, Department of Surgery, Washington University School of Medicine, Washington University in St. Louis, St. Louis, MO, USA

Submitted 17 May 2017: Final revision received 6 February 2018: Accepted 24 April 2018: First published online 1 June 2018

\begin{abstract}
Objective: We aimed to assess the maternal and family determinants of four anthropometric typologies at the household level in Colombia for the years 2000, 2005 and 2010.

Design: We classified children $<5$ years old according to height-for-age $Z$-score $(<-2)$ and BMI-for-age $Z$-score $(>2)$ to assess stunting and overweight/obesity, respectively; mothers were categorized according to BMI to assess underweight $\left(<18.5 \mathrm{~kg} / \mathrm{m}^{2}\right)$ and overweight/obesity $\left(\geq 25.0 \mathrm{~kg} / \mathrm{m}^{2}\right)$. At the household level, we established four final anthropometric typologies: normal, underweight, overweight and dual-burden households. Separate polytomous logistic regression models for each of the surveyed years were developed to examine several maternal and familial determinants of the different anthropometric typologies.

Setting: National and sub-regional (urban and rural) representative samples from Colombia, South America.

Subjects: Drawing on data from three waves of Colombia's Demographic and Health Survey/Encuesta Nacional de Salud (DHS/ENDS), we examined individual and household information from mothers (18-49 years) and their children (birth5 years).

Results: Higher parity was associated with an increased likelihood of overweight and dual burden. Higher levels of maternal education were correlated with lower prevalence of overweight, underweight and dual burden of malnutrition in all data collection waves. In 2010, participation in nutrition programmes for children $<5$ years, being an indigenous household, food purchase decisions by the mother and food security classification were also associated with the four anthropometric typologies.

Conclusions: Results suggest that maternal and family correlates of certain anthropometric typologies at the household level may be used to better frame policies aimed at improving social conditions and nutrition outcomes.
\end{abstract}

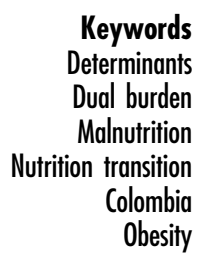

The association between family socio-economic status (SES) and undernutrition in low- and middle-income countries ${ }^{(1-4)}$ has been documented in several observational studies. Generally, malnourishment is more common among children and adolescents from households with low SES compared with children and adolescents from households that are more affluent ${ }^{(5)}$. This association can be partly explained by inadequate access to high-quality food, which itself is largely determined by household income. Another important explanation is that poor households have limited access to basic services like sanitation and potable water, which have a detrimental effect on the child's health and nutritional status $^{(6,7)}$. There is evidence of an increasingly inverse relationship between SES and the prevalence of overweight 
and obesity in middle-income countries, mainly among women $^{(8-11)}$. A systematic review conducted by Dinsa et $a l .{ }^{(12)}$ found that in low-income countries or in countries with a low Human Development Index, the association between SES and obesity appears to be positive for both men and women: that is, the more affluent and/or those with higher educational attainment are more likely to be obese. However, in middle-income countries or in countries with a medium Human Development Index, the association becomes mixed for men and mainly negative for women. Higher prevalence of overweight has also been documented among disadvantaged and vulnerable population groups such as indigenous people in low- and middle-income countries $^{(11,13,14)}$. This transition, which has already occurred in many other countries (e.g. the USA, Mexico and Brazil), is currently underway in Colombia. Overweight and obesity are growing at a faster rate among the most disadvantaged groups in Colombia including low-SES, indigenous and rural households ${ }^{(15)}$.

There is also a large body of evidence on how maternal characteristics determine malnutrition status of the child, both for undernutrition and overweight/obesity. Malnutrition determinants that have been explored in prior studies include maternal age, maternal weight, maternal education, parity and indigenous ethnicity ${ }^{(16-18)}$. McDonald $e{ } a l{ }^{(19)}$ found that low maternal parity was positively associated with childhood overweight in Bogota. Another study found higher levels of mother's education to be highly correlated with a lower prevalence of stunting ${ }^{(16)}$. This same study found that mother's overweight was positively associated with overweight of the child $^{(16)}$. A study conducted among four Andean countries, including Colombia, found that prevalence of stunting among the indigenous population was at least three times higher than among non-indigenous populations ${ }^{(20)}$. Regarding maternal age, data from a large cohort study from low- and middle-income countries found that older maternal age was associated with less stunting ${ }^{(21)}$.

Family dynamics such as composition of the family and work status of the mother have been found to be associated with a child's nutritional status. A study conducted by Crepinsek et al. found that children and adolescents whose mothers worked full time had lower diet quality and variety, with reduced consumption of fibre and $\mathrm{Fe}$, and higher consumption of soft drinks and packaged foods $^{(22)}$. A recent study conducted in Bogota among 7000 school-aged children found that those from high SES under their grandparents' care were more likely to be undernourished than children not under grandparents' care, likely due to consumption of less food and also less nutritious foods by the former group ${ }^{(23)}$.

Another study conducted in Bogota revealed that parity, maternal age and single-parent households were positively related with household food insecurity and inversely related to household income and home assets. In this same study, children from families with food insecurity were more likely to be underweight than those from foodsecure families and household hunger was positively associated with underweight mothers ${ }^{(24)}$. In the Colombia region of Antioquia, Hackett et al. found that household food insecurity was positively associated with child stunting and underweight ${ }^{(25)}$.

Despite this evidence, the majority of studies conducted in Colombia have examined the determinants of the nutrition transition at the individual level; very few have explored this issue considering typologies of nutritional status at the household level. In addition, there is not a clear understanding of how the relationships of the familial and household determinants have changed over time, which can provide insights to guide policy actions. Moreover, only a few studies have focused on the dual burden of malnutrition in Colombia, and none of these have established differences between socio-economic characteristics.

The goal of the present study was to assess several maternal and familial determinants of the different anthropometric typologies in the nutrition transition at the household level in 2000, 2005 and 2010. Variables included in the analyses were selected according to existing evidence from Colombia ${ }^{(15,16,18,19,24-26)}$. For the year 2010, we were also able to examine additional variables introduced that year, including the correlation between purchasing decisions at the household level, participation in government-subsidized nutrition programmes for children younger than 5 years, indigenous households and food security.

\section{Methods}

\section{Data description}

We performed a secondary data analysis of three crosssectional, nationally representative samples using the Demographic and Health Surveys/Encuesta Nacional de Salud (DHS/ENDS 2000, 2005 and 2010) from Colombia. The DHS are a series of surveys collected every 5 years to identify health, mental health, women's empowerment, and problems associated with sexual and reproductive health. For the years 2005 and 2010 the DHS was linked to Colombia's National Nutrition Survey, a survey assessing population nutrition. Household and individual questionnaires include questions on housing and living conditions and on the characteristics of all persons living within the household. Information on maternal variables and information from all children aged 5 years or younger were used in the current analysis. Objectively measured anthropometric indicators of mothers aged 18-49 years and of children aged 5 years or younger were also gathered during these surveys and used in the current analysis. These surveys used a probabilistic, multistage, stratified cluster sampling design to identify and select sampling units, households and individuals, which guaranteed 
national and sub-regional representativeness. There was a lower representation from high-SES households in the surveys, which reflects the actual distribution of this population group in the country (less than $6 \%$ ). Response rates ranged from 74.3 to $85.0 \%$ for BMI measures. Detailed information about the sampling design for the DHS in Colombia can be found elsewhere ${ }^{(27)}$.

The present analysis used information from children younger than 5 years of age and their mothers aged 18 to 49 years (excluding pregnant women and homes with more than one eligible mother).

\section{Measures and variables}

Weight and height were measured directly by trained DHS staff, using standardized measuring equipment. Weight was measured to the nearest $1.0 \mathrm{~kg}$, with participants wearing light clothing and without shoes, using a digital weighing scale (SECA model 770, Brooklyn, NY, USA). Height was measured to the nearest $1.0 \mathrm{~cm}$ using a portable stadiometer (Shorr Productions, Olney, MD, USA). Length was measured (in the prone position) in children under 2 years old and height was measured (in the standing position) in children aged 2 years or older.

\section{Dependent variables}

Nutritional status of children. First, all children aged 0-5 years from eligible households were classified according to height-for-age $Z$-score (HAZ) to assess stunting $(\mathrm{HAZ}<-2)$. Overweight and obesity in children was determined using a BMI-for-age $Z$-score (BMIZ) cut-off point of $>2$ according to the WHO guidelines ${ }^{(28)}$.

Nutritional status of mothers. Mothers' BMI was determined using the WHO cut-off points as underweight $\left(<18.5 \mathrm{~kg} / \mathrm{m}^{2}\right)$, overweight $\left(25.0-29.9 \mathrm{~kg} / \mathrm{m}^{2}\right)$ or obese $\left(\geq 30 \cdot 0 \mathrm{~kg} / \mathrm{m}^{2}\right)$. The categories of overweight and obese were merged.

Anthropometric typologies. Four mutually exclusive categories were developed based on child and maternal nutritional status. To derive these categories, nineteen possible combinations of anthropometric status were obtained and were grouped according to the most prevalent distribution within the category. More information about how each category was classified and obtained can be found elsewhere ${ }^{(16)}$.

1. Normal households: No stunting or obesity among any of the children, and the mother has a normal BMI.

2. Underweight households: At least one child is stunted, the remaining children can be normal, and the mother is underweight.

3. Overweight households: At least one child is obese, the remaining children can be normal, and the mother is overweight/obese or normal.

4. Dual-burden households: At least one child is stunted, the remaining children can be normal, and the mother is overweight/obese.

\section{Independent variables}

Maternal variables. Several maternal variables were included in the present study. They were categorized into different groups depending on prior studies exploring similar topics, as well as based on the efficiency of the statistical models. These variables were maternal age (categorized in three groups: 18-30, 31-39 and 40-49 years), maternal education (categorized in three groups: no formal education, elementary school and high school or more) and maternal parity (classified as one child $v$. two or more children).

Family variables. Family variables included in the present study were area of residence (urban $v$. rural), indigenous household (yes $v$. no), female head of household (yes $v$. no) and household economic status (measured with a wealth index proposed by Rutstein and Johnson ${ }^{(29)}$ and developed for use in DHS). The wealth index assesses the presence in the household of a range of assets, such as television, type of flooring, water supply, refrigerator, electricity, radio, television and domestic servant. The index is then estimated via principal components. For the present study, we used the following quintile categories of the wealth index already calculated and included in the survey: first (poorest), second and third (middle), and fourth and fifth (richest). Food purchase decisions were defined taking account of who in the home decides which foods to purchase (mother, father, other). Food security was measured with the scale developed and adapted by Alvarez et al. ${ }^{(30)}$ in 1624 homes in the State of Antioquia, Colombia, that was also used and validated by Lorenzana and Mercado ${ }^{(31)}$ in Venezuela. The scale is based on the original scale developed by Wehler et al. ${ }^{(32)}$ and classifies homes as food secure, low food insecurity, moderate food insecurity and severe food insecurity. Family type was categorized into two groups: nuclear (mother, father, and children) $v$. extended (grandparents, uncles, aunts, etc.) Participants were also asked if they had received assistance from government nutrition programmes for children under 5 years old; this variable was categorized as yes $v$. no.

\section{Data analysis}

Polytomous logistic regression models were conducted exploring the associations between household anthropometric typologies and several maternal and family determinants for 2000, 2005 and 2010, including maternal age, maternal education, mother's parity, wealth index, area of residence, family type and female head of household, using normal households as the reference category. Additional variables entered in the model for the year 2010 (the only year where this information was available) included indigenous ethnicity, food security classification, food purchase decisions and participation in government nutrition programmes for children younger than 5 years. OR and $95 \%$ CI were calculated to test for statistical 
significance. Collinearity between variables was assessed by calculating variance inflation factors and correlation coefficients. None of the variables included in the models presented correlation coefficients higher than 0.6 or variance inflation factor values higher than 3.2. A $P$ value greater than 0.05 and less than 0.10 was used to determine marginal statistical significance, while a $P$ value less than 0.05 determined statistical significance ${ }^{(33)}$. All analyses accounted for the complex sampling design and used the appropriate sampling weights. The statistical software package Stata version 12 was used for all statistical analyses.

\section{Results}

Descriptive characteristics of the sample for all three DHS/ ENDS (2000, 2005 and 2010) are presented in Table 1. The majority of the sample (59\% in 2000, $60 \%$ in 2005, 61\% in 2010) was classified in the 18-30 years category for maternal age. In 2000, $15 \%$ of the sample was classified in the highest quintile category of the wealth index, while
22 and $24 \%$ were classified in the lowest and the second quintile, respectively. The distribution did not change significantly from the second to the highest wealth quintile, but the percentage of the population in the lowest wealth quintile was higher in 2010 at $33 \%$ of the sample.

\section{Determinants of anthropometric typologies in the year 2000}

As shown in Table 2, families in the second-highest wealth category (OR $=0.5 ; 95 \% \mathrm{CI} 0 \cdot 2,0 \cdot 8)$ were less likely to be classified as underweight typology compared with normal typology. Parity (two or more children: $O R=1.6 ; 95 \%$ CI $1 \cdot 3,2 \cdot 0)$ and maternal age $(31-39$ years: $\mathrm{OR}=1 \cdot 8 ; 95 \%$ CI 1.4, 2.1; 40-49 years: $O R=2 \cdot 4$; $95 \%$ CI $1.5,3.6)$ were associated with the prevalence of overweight anthropometric typology compared with normal typology. The second $(\mathrm{OR}=1 \cdot 4 ; 95 \% \mathrm{CI} 1 \cdot 0,2 \cdot 0)$, third (OR $=1 \cdot 4 ; 95 \% \mathrm{CI} 1 \cdot 0$, $2 \cdot 1)$, fourth $(\mathrm{OR}=1 \cdot 8 ; 95 \% \mathrm{CI} 1 \cdot 1,2 \cdot 7)$ and fifth $(\mathrm{OR}=1 \cdot 6$; $95 \%$ CI $1.0,2.5)$ wealth index categories were positively associated with the likelihood of being classified in the

Table 1 Descriptive characteristics of the sample of mothers (18-49 years) and their children (birth-5 years) from three waves of the Demographic and Health Survey/Encuesta Nacional de Salud (DHS/ENDS) in Colombia

\begin{tabular}{|c|c|c|c|c|c|c|}
\hline & \multicolumn{2}{|c|}{2000} & \multicolumn{2}{|c|}{2005} & \multicolumn{2}{|c|}{2010} \\
\hline & $n$ or Mean & $\%$ or SD & $n$ or Mean & $\%$ or SD & $n$ or Mean & $\%$ or SD \\
\hline \multicolumn{7}{|l|}{ Anthropometric typology } \\
\hline Normal & 1182 & $41 \cdot 1$ & 3574 & 41.9 & 4301 & $39 \cdot 3$ \\
\hline Overweight & 1090 & 38.5 & 3289 & $38 \cdot 2$ & 5085 & $45 \cdot 3$ \\
\hline Underweight & 394 & $13 \cdot 1$ & 1158 & $13 \cdot 0$ & 1250 & $10 \cdot 0$ \\
\hline Dual burden & 210 & $7 \cdot 1$ & 577 & $7 \cdot 0$ & 713 & $5 \cdot 1$ \\
\hline \multicolumn{7}{|l|}{ Maternal age } \\
\hline $18-29$ years & 1843 & 59 & 5675 & 60 & 7017 & 61 \\
\hline 30-39 years & 1091 & 35 & 3196 & 34 & 3678 & 32 \\
\hline 40-49 years & 188 & 6 & 565 & 6 & 835 & 7 \\
\hline \multicolumn{7}{|l|}{ Wealth index quintile } \\
\hline Lowest & 719 & 22 & 2367 & 25 & 3850 & 33 \\
\hline Second & 774 & 24 & 2651 & 28 & 3131 & 27 \\
\hline Middle & 732 & 22 & 2090 & 22 & 2230 & 19 \\
\hline Fourth & 552 & 17 & 1420 & 15 & 1449 & 13 \\
\hline Highest & 490 & 15 & 908 & 10 & 870 & 8 \\
\hline \multicolumn{7}{|l|}{ Area of residence } \\
\hline Urban & 2272 & 70 & 6697 & 71 & 7522 & 65 \\
\hline Rural & 995 & 30 & 2739 & 29 & 4008 & 35 \\
\hline \multicolumn{7}{|l|}{ Maternal education } \\
\hline No formal education & 111 & 4 & 335 & 4 & 277 & 2 \\
\hline Elementary & 2029 & 65 & 5458 & 58 & 6122 & 53 \\
\hline High school or more & 982 & 31 & 3643 & 38 & 5131 & 45 \\
\hline Female head of household & 681 & 21 & 2133 & 23 & 2966 & 26 \\
\hline \multicolumn{7}{|l|}{ Family type } \\
\hline Nuclear & 1669 & 54 & 5372 & 57 & 6890 & 60 \\
\hline Extended & 1453 & 46 & 4064 & 43 & 4640 & 40 \\
\hline Household size, mean and SD & 5.5 & $2 \cdot 3$ & $5 \cdot 3$ & $2 \cdot 1$ & $5 \cdot 1$ & $1 \cdot 8$ \\
\hline Children $<5$ years, mean and SD & 1.3 & 0.6 & $1 \cdot 3$ & 0.5 & $1 \cdot 2$ & 0.5 \\
\hline Food purchase decisions (mother) & - & - & - & - & 8836 & 77 \\
\hline \multicolumn{7}{|l|}{ Food security } \\
\hline Secure & - & - & - & - & 3895 & 34 \\
\hline Low insecurity & - & - & - & - & 4628 & 40 \\
\hline Moderate insecurity & - & - & - & - & 1885 & 16 \\
\hline Severe insecurity & - & - & - & - & 1116 & 10 \\
\hline Indigenous household & - & - & - & - & 1384 & 12 \\
\hline Participates in nutrition programme for children $<5$ years & - & - & - & - & 5961 & 52 \\
\hline
\end{tabular}

Data presented are $n$ and \% unless indicated otherwise. 
Table 2 Maternal and familial determinants of anthropometric typologies compared with normal typology in 2000 ( $n$ 2863), Demographic and Health Survey/Encuesta Nacional de Salud (DHS/ENDS) in Colombia

\begin{tabular}{|c|c|c|c|c|c|c|}
\hline & \multicolumn{2}{|c|}{ Underweight typology (n 1090) } & \multicolumn{2}{|c|}{ Overweight typology (n 1576) } & \multicolumn{2}{|c|}{ Dual-burden typology ( $n$ 210) } \\
\hline & Adjusted OR† & $95 \% \mathrm{Cl}$ & Adjusted OR $†$ & $95 \% \mathrm{Cl}$ & Adjusted OR $\dagger$ & $95 \% \mathrm{Cl}$ \\
\hline \multicolumn{7}{|l|}{ Maternal indicators } \\
\hline \multicolumn{7}{|l|}{ Parity } \\
\hline One child & \multicolumn{2}{|c|}{ Ref. } & \multicolumn{2}{|c|}{ Ref. } & \multicolumn{2}{|c|}{ Ref. } \\
\hline Two or more children & 1.2 & $0.8,1.6$ & $1 \cdot 6^{\star \star \star}$ & $1 \cdot 3,2 \cdot 0$ & 1.5 & $0.9,2.4$ \\
\hline Education & & & & & & \\
\hline No education & \multicolumn{2}{|c|}{ Ref. } & \multicolumn{2}{|c|}{ Ref. } & \multicolumn{2}{|c|}{ Ref. } \\
\hline Elementary & 1.3 & $0.7,2.4$ & $1 \cdot 1$ & $0.6,1.8$ & 1.6 & $0.7,3.5$ \\
\hline High school or more & 0.9 & $0.5,1.9$ & 0.9 & $0.5,1.7$ & 0.9 & $0.4,2.4$ \\
\hline Age & & & \multirow{2}{*}{\multicolumn{2}{|c|}{ Ref. }} & \multirow{2}{*}{\multicolumn{2}{|c|}{ Ref. }} \\
\hline 18-30 years & \multicolumn{2}{|c|}{ Ref. } & & & & \\
\hline $31-39$ years & 1.1 & $0.7,1.4$ & $1 \cdot 8^{\star \star \star}$ & $1 \cdot 4,2 \cdot 1$ & 1.2 & $0.9,1.4$ \\
\hline $40-49$ years & 0.9 & $0.4,1.7$ & $2 \cdot 4^{\star \star \star}$ & $1.5,3.6$ & $1 \cdot 3^{\star \star \star}$ & $0.9,1.8$ \\
\hline \multicolumn{7}{|l|}{ Family indicators } \\
\hline \multicolumn{7}{|l|}{ Wealth index quintile } \\
\hline Lowest & \multicolumn{2}{|c|}{ Ref. } & \multicolumn{2}{|c|}{ Ref. } & \multicolumn{2}{|c|}{ Ref. } \\
\hline Second & 1.1 & $0.7,1.6$ & $1.4^{\star \star}$ & $1 \cdot 0,2 \cdot 0$ & 1.3 & $0.7,2.0$ \\
\hline Middle & 0.7 & $0.4,1.2$ & $1.4^{\star}$ & $1 \cdot 0,2 \cdot 1$ & 0.9 & $0.4,1.7$ \\
\hline Fourth & $0.5^{\star \star}$ & $0.2,0.8$ & $1.8^{* *}$ & $1 \cdot 1,2 \cdot 7$ & 0.7 & $0.3,1.3$ \\
\hline Highest & $0 \cdot 6^{(*)}$ & $0.3,1 \cdot 1$ & $1 \cdot 6^{\star}$ & $1.0,2.5$ & 0.5 & $0.2,1 \cdot 2$ \\
\hline Area of residence & & & \multirow{2}{*}{\multicolumn{2}{|c|}{ Ref. }} & \multirow{2}{*}{\multicolumn{2}{|c|}{ Ref. }} \\
\hline Urban & \multicolumn{2}{|c|}{ Ref. } & & & & \\
\hline Rural & 1.0 & $0.7,1.4$ & $1 \cdot 2$ & $0.8,1.6$ & $1 \cdot 1$ & $0.6,1 \cdot 7$ \\
\hline Female head of household & 1.0 & $0.7,1.4$ & $0.8^{*}$ & $0.6,1.0$ & 0.8 & $0.5,1.3$ \\
\hline Household size & $1 \cdot 1^{\star \star}$ & $1.0,1.2$ & 0.9 & $0.9,1.0$ & $1 \cdot 1^{\star \star}$ & $1 \cdot 0,1 \cdot 2$ \\
\hline Children $<5$ years & $2 \cdot 1^{\star \star \star}$ & $1.5,2.6$ & 0.9 & $0.7,1 \cdot 1$ & $1.9^{\star \star \star}$ & $1 \cdot 4,2 \cdot 6$ \\
\hline \multicolumn{7}{|l|}{ Family type } \\
\hline Nuclear & \multicolumn{2}{|c|}{ Ref. } & \multicolumn{2}{|c|}{ Ref. } & \multicolumn{2}{|c|}{ Ref. } \\
\hline Extended & 0.9 & $0.6,1 \cdot 2$ & 0.9 & $0.7,1.2$ & 0.9 & $0.5,1.3$ \\
\hline
\end{tabular}

Ref., reference category.

${ }^{(\star)} P<0.1,{ }^{\star} P<0.05,{ }^{\star \star} P<0.01,{ }^{\star \star *} P<0.001$.

†Adjusted by all variables included in the models.

overweight typology compared with normal typology. The larger the household size (OR $=1 \cdot 1 ; 95 \% \mathrm{CI} 1 \cdot 0,1 \cdot 2)$ and the greater the number of children younger than 5 years $(\mathrm{OR}=1.9 ; 95 \% \mathrm{CI} 1.4,2.6)$ residing in the house, the greater the likelihood to be classified in the dual-burden typology.

\section{Determinants of anthropometric typologies in the year 2005}

As shown in Table 3, maternal education of high school or more $(\mathrm{OR}=0 \cdot 6 ; 95 \% \mathrm{CI} 0.3,0.9)$ was associated with a lower likelihood of being classified in the underweight typology compared with normal typology. Families in the second $(\mathrm{OR}=0 \cdot 7 ; 95 \% \mathrm{CI} 0 \cdot 5,0 \cdot 8)$, third $(\mathrm{OR}=0.5 ; 95 \% \mathrm{CI}$ $0.4,0.7)$, fourth $(\mathrm{OR}=0.5 ; 95 \%$ CI $0.3,0.7)$ and fifth $(\mathrm{OR}=0 \cdot 2 ; 95 \%$ CI $0 \cdot 1,0 \cdot 4)$ wealth index categories were less likely to be classified in the underweight typology compared with normal typology. Having two or more children $(\mathrm{OR}=1 \cdot 6 ; 95 \% \mathrm{CI} 1.3,1 \cdot 8)$ significantly increased the likelihood that a home was classified in the overweight typology $v$. normal typology. Homes with mothers classified in the elementary category of education were more likely to be classified in the overweight typology compared with normal typology $(\mathrm{OR}=1 \cdot 4 ; 95 \%$ CI $1 \cdot 0,2 \cdot 0)$. As maternal age increased $(31-39$ years: $\mathrm{OR}=1 \cdot 6 ; 95 \%$ CI $1.4,1 \cdot 8$; 40-49 years: $O R=2 \cdot 0 ; 95 \%$ CI $1 \cdot 5,2 \cdot 6)$ there was a greater likelihood that a household would be classified in the overweight typology. The second $(\mathrm{OR}=1 \cdot 3$; $95 \%$ CI $1.0,1.6)$, third (OR $=1.4 ; 95 \%$ CI $1.0,1 \cdot 7)$, fourth $(\mathrm{OR}=1 \cdot 5 ; 95 \% \mathrm{CI} 1 \cdot 2,2 \cdot 0)$ and fifth $(\mathrm{OR}=1 \cdot 5 ; 95 \% \mathrm{CI} 1 \cdot 1$, $2 \cdot 0)$ wealth index categories were positively associated with the likelihood of being classified in the overweight typology compared with normal typology.

Maternal parity of two or more children (OR $=2 \cdot 2 ; 95 \%$ CI $1.4,3 \cdot 2$ ) was associated with a higher likelihood of being classified as a dual-burden household compared with a normal household. Homes with maternal education of high school or more (OR=0.6; $95 \%$ CI $0.3,1.0)$ were less likely to be classified in the dual-burden typology compared with normal typology. Homes in the highest wealth index quintile (OR $=0.5 ; 95 \%$ CI 0.2, 0.9) were less likely to be classified as a dual-burden household compared with a normal household. The greater the number of children younger than 5 years residing in the household ( OR $=2 \cdot 2 ; 95 \%$ CI $1 \cdot 8,2 \cdot 8)$, the more likely to be classified in the dual-burden typology.

\section{Determinants of anthropometric typologies in the year 2010}

As shown in Table 4, maternal parity of two or more children $(\mathrm{OR}=0.8 ; 95 \%$ CI $0.6,0.9)$ was negatively 
Table 3 Maternal and familial determinants of anthropometric typologies compared with normal typology in 2005 ( $n$ 8588), Demographic and Health Survey/Encuesta Nacional de Salud (DHS/ENDS) in Colombia

\begin{tabular}{|c|c|c|c|c|c|c|}
\hline & \multicolumn{2}{|c|}{ Underweight typology ( $n$ 1158) } & \multicolumn{2}{|c|}{ Overweight typology ( $n$ 3289) } & \multicolumn{2}{|c|}{ Dual-burden typology ( $n$ 577) } \\
\hline & Adjusted OR $†$ & $95 \% \mathrm{Cl}$ & Adjusted OR $\dagger$ & $95 \% \mathrm{Cl}$ & Adjusted OR† & $95 \% \mathrm{Cl}$ \\
\hline \multicolumn{7}{|l|}{ Maternal indicators } \\
\hline \multicolumn{7}{|l|}{ Parity } \\
\hline One child & \multicolumn{2}{|c|}{ Ref. } & \multicolumn{2}{|c|}{ Ref. } & \multicolumn{2}{|c|}{ Ref. } \\
\hline Two or more children & 0.9 & $0 \cdot 7,1 \cdot 2$ & $1 \cdot 6^{\star \star \star}$ & $1 \cdot 3,1 \cdot 8$ & $2 \cdot 2^{\star \star \star}$ & $1 \cdot 4,3 \cdot 2$ \\
\hline Education & & & & & & \\
\hline No education & \multicolumn{2}{|c|}{ Ref. } & \multicolumn{2}{|c|}{ Ref. } & \multicolumn{2}{|c|}{ Ref. } \\
\hline Elementary & 0.7 & $0.5,1 \cdot 1$ & $1 \cdot 4^{\star}$ & $1 \cdot 0,2 \cdot 0$ & 0.8 & $0.4,1 \cdot 2$ \\
\hline High school or more & $0 \cdot 6^{\star \star}$ & $0.3,0.9$ & $1 \cdot 4^{(\star)}$ & $0 \cdot 9,2 \cdot 1$ & $0.6^{*}$ & $0.3,1.0$ \\
\hline Age & & & \multirow{2}{*}{\multicolumn{2}{|c|}{ Ref. }} & \multirow{2}{*}{\multicolumn{2}{|c|}{ Ref. }} \\
\hline $18-30$ years & \multicolumn{2}{|c|}{ Ref. } & & & & \\
\hline 31-39 years & $0 \cdot 8^{(*)}$ & $0.6,1.0$ & $1 \cdot 6^{\star \star \star}$ & $1.4,1.8$ & $1 \cdot 4^{\star}$ & $1 \cdot 0,1 \cdot 8$ \\
\hline 40-49 years & 0.8 & $0.5,1.3$ & $2 \cdot 0^{\star \star \star}$ & $1.5,2.6$ & $2 \cdot 1^{\star \star \star}$ & $1 \cdot 3,3 \cdot 5$ \\
\hline \multicolumn{7}{|l|}{ Family indicators } \\
\hline \multicolumn{7}{|l|}{ Wealth index quintile } \\
\hline Lowest & \multicolumn{2}{|c|}{ Ref. } & \multicolumn{2}{|c|}{ Ref. } & \multicolumn{2}{|c|}{ Ref. } \\
\hline Second & $0.7^{\star \star \star}$ & $0.5,0.8$ & $1 \cdot 3^{\star \star}$ & $1 \cdot 0,1 \cdot 6$ & 0.9 & $0 \cdot 6,1 \cdot 2$ \\
\hline Middle & $0.5^{\star \star \star}$ & $0.4,0.7$ & $1.4^{\star *}$ & $1 \cdot 0,1 \cdot 7$ & 0.9 & $0.6,1.4$ \\
\hline Fourth & $0.5^{\star \star \star}$ & $0.3,0.7$ & $1.5^{\star \star \star}$ & $1 \cdot 2,2 \cdot 0$ & 0.6 & $0.3,1 \cdot 1$ \\
\hline Highest & $0 \cdot 2^{\star \star \star}$ & $0 \cdot 1,0.4$ & $1 \cdot 5^{\star \star}$ & $1 \cdot 1,2 \cdot 0$ & $0.5^{*}$ & $0.2,0.9$ \\
\hline \multicolumn{7}{|l|}{ Area of residence } \\
\hline Urban & \multicolumn{2}{|c|}{ Ref. } & \multicolumn{2}{|c|}{ Ref. } & \multicolumn{2}{|c|}{ Ref. } \\
\hline Rural & 0.9 & $0.7,1 \cdot 1$ & $1 \cdot 2^{*}$ & $1 \cdot 0,1.4$ & $1 \cdot 3$ & $0.9,1.7$ \\
\hline Female head of household & 0.9 & $0 \cdot 7,1 \cdot 1$ & $0.8^{*}$ & $0.7,0.9$ & 0.9 & $0 \cdot 6,1 \cdot 2$ \\
\hline Household size & $1 \cdot 1^{\star \star}$ & $1 \cdot 0,1 \cdot 1$ & 0.9 & $0.9,1.0$ & $1 \cdot 1^{(\star)}$ & $0.9,1.1$ \\
\hline Children $<5$ years & $2 \cdot 1^{\star \star \star}$ & $1 \cdot 7,2 \cdot 5$ & 0.9 & $0.8,1 \cdot 1$ & $2 \cdot 2^{\star \star \star}$ & $1 \cdot 8,2 \cdot 8$ \\
\hline \multicolumn{7}{|l|}{ Family type } \\
\hline Nuclear & \multicolumn{2}{|c|}{ Ref. } & \multicolumn{2}{|c|}{ Ref. } & \multicolumn{2}{|c|}{ Ref. } \\
\hline Extended & 0.9 & $0.7,1 \cdot 2$ & $1 \cdot 1$ & $0.9,1 \cdot 2$ & 1.0 & $0.7,1.4$ \\
\hline
\end{tabular}

Ref., reference category.

${ }^{(\star)} P<0.1,{ }^{\star} P<0.05,{ }^{\star \star} P<0.01,{ }^{\star \star \star} P<0.001$.

†Adjusted by all variables included in the models.

associated with the likelihood of being classified in the underweight typology compared with normal typology. High school or more maternal education $(\mathrm{OR}=0.3 ; 95 \%$ CI $0 \cdot 2,0 \cdot 6)$ was associated with a lower likelihood of being classified as an underweight household. Families in the highest wealth index category $(\mathrm{OR}=0.6 ; 95 \% \mathrm{CI} 0 \cdot 3,0 \cdot 9)$ were less likely to be classified as an underweight household compared with normal households. Homes where food purchasing decisions were made by the mother $(\mathrm{OR}=1 \cdot 2 ; 95 \% \mathrm{CI} 1 \cdot 0,1 \cdot 5)$ were more likely to be classified as an underweight household. Households classified as indigenous (OR $=2 \cdot 1 ; 95 \%$ CI $1 \cdot 5,2 \cdot 7)$ were more likely to be classified in the underweight typology.

Having two or more children (OR $=1.5 ; 95 \%$ CI 1.3, 1.7) increased the likelihood that a home would be classified in the overweight typology $v$. normal typology. As maternal age increased $(31-39$ years: $\mathrm{OR}=1.5 ; 95 \% \mathrm{CI} 1.3,1.7$; $40-49$ years: $\mathrm{OR}=2 \cdot 1 ; 95 \% \mathrm{CI} 1 \cdot 6,2 \cdot 6$ ) there was a greater likelihood that a household would be classified in the overweight typology. Homes where food purchasing decisions were made by the mother $(\mathrm{OR}=0 \cdot 8 ; 95 \% \mathrm{CI} 0 \cdot 6$, $0 \cdot 8$ ) were less likely to be classified as an overweight household. Homes classified as indigenous $(\mathrm{OR}=1.4$; $95 \%$ CI $1 \cdot 1,1 \cdot 8)$ were more likely to be classified as an overweight household.
Maternal parity of two or more children (OR $=1.4 ; 95 \%$ CI $1.0,1.9)$ was associated with a higher likelihood of being classified as a dual-burden household compared with a normal household. As maternal age increased (31-39 years: $\mathrm{OR}=1 \cdot 4 ; 95 \%$ CI $1 \cdot 1,1 \cdot 8$; $40-49$ years: $\mathrm{OR}=1 \cdot 8 ; 95 \%$ CI $1 \cdot 0,2 \cdot 8)$, so did the likelihood that a household would be classified in the dual-burden typology. Homes where food purchasing decisions were made by the mother $(\mathrm{OR}=0.5 ; 95 \% \mathrm{CI} 0.3,0.7)$ were less likely to be classified as a dual-burden household. Homes in the category of moderate food insecurity $(\mathrm{OR}=1 \cdot 6$; $95 \%$ CI 1.1, 2.3) were more likely to be classified as a dualburden typology household compared with normal typology household. Finally, homes classified as indigenous (OR $=2 \cdot 1 ; 95 \%$ CI $1.4,3.0)$ were more likely to be classified as a dual-burden household.

\section{Discussion}

The present study found several maternal and family characteristics to be associated with various anthropometric typologies (namely overweight, underweight and the dual burden of malnutrition) at the household level. The degree and significance of the associations varied 
Table 4 Maternal and familial determinants of anthropometric typologies compared with normal typology in 2010 ( $n$ 11248), Demographic and Health Survey/Encuesta Nacional de Salud (DHS/ENDS) in Colombia

\begin{tabular}{|c|c|c|c|c|c|c|}
\hline & \multicolumn{2}{|c|}{$\begin{array}{l}\text { Underweight typology } \\
\text { (n 1250) }\end{array}$} & \multicolumn{2}{|c|}{$\begin{array}{l}\text { Overweight typology } \\
(n \text { 5085) }\end{array}$} & \multicolumn{2}{|c|}{$\begin{array}{l}\text { Dual-burden typology } \\
\qquad(n 713)\end{array}$} \\
\hline & Adjusted OR $†$ & $95 \% \mathrm{Cl}$ & Adjusted OR† & $95 \% \mathrm{Cl}$ & Adjusted OR† & $95 \% \mathrm{Cl}$ \\
\hline \multicolumn{7}{|l|}{ Maternal indicators } \\
\hline \multicolumn{7}{|l|}{ Parity } \\
\hline One child & \multicolumn{2}{|c|}{ Ref. } & \multicolumn{2}{|l|}{ Ref. } & \multicolumn{2}{|l|}{ Ref. } \\
\hline Two or more children & $0.8^{*}$ & $0.6,0.9$ & $1.5^{\star \star \star}$ & $1 \cdot 3,1 \cdot 7$ & $1.4^{*}$ & $1.0,1.9$ \\
\hline \multicolumn{7}{|l|}{ Education } \\
\hline No education & \multicolumn{2}{|l|}{ Ref. } & \multicolumn{2}{|l|}{ Ref. } & \multicolumn{2}{|l|}{ Ref. } \\
\hline Elementary & $0.6^{(*)}$ & $0.3,1.0$ & $1 \cdot 2$ & $0.7,1.8$ & 1.2 & $0 \cdot 6,2 \cdot 1$ \\
\hline High school or more & $0.3^{\star \star \star}$ & $0.2,0.6$ & $1 \cdot 2$ & $0 \cdot 7,1 \cdot 7$ & 0.8 & $0.4,1.5$ \\
\hline \multicolumn{7}{|l|}{ Age } \\
\hline $18-30$ years & \multicolumn{2}{|l|}{ Ref. } & \multicolumn{2}{|c|}{ Ref. } & \multicolumn{2}{|l|}{ Ref. } \\
\hline $31-39$ years & $0.8^{\star}$ & $0.6,0.9$ & $1.5^{\star \star \star}$ & $1 \cdot 3,1.7$ & $1.4^{\star \star \star}$ & $1 \cdot 1,1 \cdot 8$ \\
\hline 40-49 years & 1.0 & $0.6,1.4$ & $2 \cdot 1^{\star \star \star}$ & $1 \cdot 6,2 \cdot 6$ & $1 \cdot 8^{\star \star}$ & $1 \cdot 0,2 \cdot 8$ \\
\hline \multicolumn{7}{|l|}{ Family indicators } \\
\hline \multicolumn{7}{|l|}{ Wealth index quintile } \\
\hline Lowest & \multicolumn{2}{|c|}{ Ref. } & \multicolumn{2}{|c|}{ Ref. } & \multicolumn{2}{|l|}{ Ref. } \\
\hline Second & 0.9 & $0.6,1 \cdot 1$ & $1 \cdot 1$ & $0.9,1.2$ & $0.7^{(*)}$ & $0.5,1.0$ \\
\hline Middle & 0.8 & $0.5,1 \cdot 1$ & $1 \cdot 1$ & $0.8,1.3$ & $0.6^{*}$ & $0.4,0.9$ \\
\hline Fourth & 0.8 & $0.5,1.1$ & $1 \cdot 1$ & $0.8,1.4$ & $0.6^{(*)}$ & $0.4,1.0$ \\
\hline Highest & $0.6^{*}$ & $0.3,0.9$ & $1 \cdot 3^{(*)}$ & $0.9,1.6$ & 0.7 & $0.4,1.3$ \\
\hline Area of residence & & & \multirow{2}{*}{\multicolumn{2}{|c|}{ Ref. }} & \\
\hline Urban & \multicolumn{2}{|c|}{ Ref. } & & & Ref. & \\
\hline Rural & 1.0 & $0.7,1.3$ & 1.0 & $0.8,1 \cdot 2$ & $0.7^{(\star)}$ & $0.5,1.0$ \\
\hline Female head of household & $1 \cdot 1$ & $0.8,1.2$ & 0.9 & $0.8,1.1$ & 1.1 & $0.8,1.4$ \\
\hline Food purchase decisions by mother & $1 \cdot 2^{*}$ & $1 \cdot 0,1 \cdot 5$ & $0 \cdot 8^{* \star *}$ & $0.6,0.8$ & $0.5^{\star \star \star}$ & $0.3,0.7$ \\
\hline Food security & & & & & & \\
\hline Secure & \multicolumn{2}{|c|}{ Ref. } & \multicolumn{2}{|l|}{ Ref. } & \multicolumn{2}{|l|}{ Ref. } \\
\hline Low insecurity & $1 \cdot 1$ & $0.8,1 \cdot 3$ & 1.0 & $0.9,1.1$ & $1 \cdot 2$ & $0.8,1.6$ \\
\hline Moderate insecurity & $1 \cdot 1$ & $0.8,1.5$ & 1.0 & $0.8,1.2$ & $1.6^{\star \star \star}$ & $1 \cdot 1,2 \cdot 3$ \\
\hline Severe insecurity & $1 \cdot 1$ & $0.7,1.4$ & 0.9 & $0.7,1 \cdot 2$ & 1.4 & $0.8,2 \cdot 1$ \\
\hline Indigenous household & $2 \cdot 1^{\star \star *}$ & $1 \cdot 5,2 \cdot 7$ & $1 \cdot 4^{\star \star *}$ & $1 \cdot 1,1 \cdot 8$ & $2 \cdot 1^{* \star *}$ & $1.4,3 \cdot 0$ \\
\hline Family participates in nutrition programmes for children $<5$ years & $0.8^{(*)}$ & $0.7,1.0$ & $0.9^{(*)}$ & $0.8,1.0$ & 0.9 & $0.7,1 \cdot 1$ \\
\hline
\end{tabular}

Ref., reference category.

${ }^{\star *} P<0.1,{ }^{\star} P<0.05,{ }^{\star \star} P<0.01,{ }^{\star \star \star} P<0.001$.

†Adjusted by all variables included in the models.

between 2000, 2005 and 2010. In addition, the direction of the association varied according to the anthropometric typology. Overall, maternal variables were more often correlated with the anthropometric typologies than familylevel indicators. These findings provide evidence of a dynamic and complex nutrition transition in Colombia, which has been taking place over the last decades.

Higher parity was associated with an increased likelihood of overweight and dual burden. Similar findings have been reported elsewhere in Latin America ${ }^{(34,35)}$. Coitinho et al. reported a greater retention of weight among women with two or more children and showed that parity reduced the effects of weight loss associated with lactation ${ }^{(34)}$. Similarly, Mansour and Ajeel showed that body weight progressively and significantly increased with increasing parity ${ }^{(35)}$. A study from Peru found that multiparous women have a higher BMI as well as higher rates of overweight and obesity relative to their nulliparous counterparts, and this finding was more pronounced among young and rural women and especially those with two or more children ${ }^{(36)}$. Similarly, maternal obesity has been associated with the infant's higher fat mass at birth and higher abdominal fat accumulation, while a higher proportion of total fat mass placed abdominally in the mother has been associated with the infant's low birth weight $^{(37,38)}$. These relationships could help explain the association with the household typologies of overweight and dual burden. The exact mechanisms of how this phenomenon happens are still not clear. One possible explanation is that overweight and obese mothers are equally malnourished and may not be providing the necessary micronutrients to their infants needed for normal linear growth. Another explanation is related to household environment and the higher prevalence of high-energy-dense foods that could promote weight gain in children but that do not promote linear growth.

Maternal education was an important predictor of nutritional status of the family. The current study found that higher levels of maternal education were correlated with a lower prevalence of overweight, underweight and the dual burden of malnutrition. Similar findings have been reported in other studies from Colombia ${ }^{(16,17)}$, highlighting the importance of interventions that invest in maternal education, which directly impacts the nutritional and health outcomes of children ${ }^{(39)}$. In the present study, even though having an elementary education level was 
correlated with a lower prevalence of the overweight typology, having a high-school education was more consistently associated with a lower likelihood of being classified in the underweight, overweight and dual-burden typologies.

Unlike in 2000 and 2005, the wealth index was no longer associated with the overweight anthropometric typology in 2010. This could be an indicator of the nutrition transition underway in Colombia, in which higher purchasing power ceases to be a determinant of overweight. Similar trends over time have been reported and seen in middle-income countries such as Mexico and Brazil $^{(40)}$. This transition took place earlier in developed countries such as the USA and the UK. Countries like Mexico have reported an increase of $2.4 \%$ each year in the population of adult obese women, compared with an increase of $0.39 \%$ in the $\mathrm{USA}^{(41)}$. In many countries around the world, obesity now reflects a marker of poverty, especially in places where the food supply is plentiful $^{(42)}$. Although obesity rates are rising among all social classes, research shows that obesity is often more prevalent among those with lower SES and is beginning to be used as an indicator of social disparities ${ }^{(43)}$. The evidence from the present study partly supports this claim. Similarly, rural residency was found to be positively associated with overweight in 2005, acting as another indicator of the nutrition transition, but no association was found in 2010.

Being classified as an indigenous household in 2010 was associated with a higher likelihood of underweight, overweight and the dual burden. Indigenous populations have often been linked with undernutrition problems in Colombia, but in other countries from Latin America a higher prevalence of overweight among this population is commonly reported ${ }^{(44-46)}$. Research on the prevalence and consequences of the dual burden of malnutrition, particularly among indigenous communities, is sporadic. A study in Guatemala by Ramirez-Zea et al. ${ }^{(47)}$ documented that the greater prevalence of the dual burden of malnutrition among indigenous populations could be due to a combination of environmental and genetic risk factors. Environmental causes are like the ones experienced by indigenous populations elsewhere in the world, including Colombia, and include poverty, poor hygiene, recurrent infections, overcrowding, and inadequate clinical care and health promotion. In addition, there could be a higher genetic susceptibility that can intensify the relationship between social and environmental disadvantages, increasing morbidity in indigenous populations ${ }^{(48)}$.

As shown in the current study, Colombia is moving towards or is already in the midst of a nutrition transition; in this sense, overweight is beginning to be a problem for underprivileged and impoverished communities such as low-SES, rural and indigenous populations. However, it is likely that despite being overweight or obese, many of these communities struggle with a deficit of vital and important micronutrients that allow for normal growth in children; hence the concomitant association with the dual burden of malnutrition. Thus, families might have enough supply of energy but from foods that are of low or no nutritional value. The ubiquitous presence in low- and middle-income countries of transnational food corporations that offer inexpensive, easy-to-prepare, ultraprocessed food options will only worsen this situation ${ }^{(49)}$ unless preventive and protective measures are taken.

Our analyses revealed a high level of food insecurity (66\% of the sample), similarly to findings from other studies of Colombia ${ }^{(24)}$. In one study from Mexico, researchers found an association between a moderate level of food insecurity and the dual burden of malnutrition ${ }^{(50)}$. A moderate level of food insecurity indicates that there is a constant feeling of hunger experienced by household adults but not in children. Other studies have reported similar associations between food insecurity and the dual burden of malnutrition $^{(51-54)}$ as well as overweight and obesity ${ }^{(55-58)}$. This may be due to the same reasons behind the higher prevalence of overweight among disadvantaged populations, namely a predominance of low-quality and lowvariety diets that are cheap and increase the likelihood of overweight and obesity among adults, while at the same time promoting micronutrient deficiencies that affect growth in children.

Government nutrition assistance programmes known as conditional cash transfers have been widely implemented in Latin America as a strategy to improve the health, nutritional and economic outcomes of impoverished families. Although these programmes have the potential to improve nutritional status, they can also be contributing to obesity and the dual burden of malnutrition by supporting unhealthy diets ${ }^{(59,60)}$. The current study found that more than half $(52 \%)$ of the families in the sample for 2010 were participating in nutrition government programmes for children under 5 years of age; this is likely due to the high proportion of low-income families included in the study.

Some limitations of the present study, common in secondary data analyses, should be noted. These include the inability to change questions and obtain additional information from the respondents. Many of the variables and information from the surveys used herein were selfreported and have the well-known sources of error, including measurement bias and social desirability. Additionally, it is impossible to establish any causal relationships due to the study's cross-sectional nature. The use of large data sets for secondary data analysis can present some challenges related to the lack of information and clarity about code books and organization of the variables; this limitation was minimized by working closely with the institutions and statisticians who were involved in the general surveys and in charge of developing the sampling strategy. However, biases and measurement issues could have been present in the information from 
the data sets including anthropometric measurements. A different sampling frame was used in 2000, which limits the reach of the conclusions for the Orinoquia and Amazonia regions.

Despite these limitations, the present study is important as it relies on objectively measured anthropometric measures such as height, weight and length taken by trained and experienced staff. To our knowledge, the current study is the first published from Colombia, the second largest country in Latin America, to explore determinants of various types of malnutrition at the national level and across time.

Results from the present study indicate the potential for investment in programmes and policies that enhance maternal education, reducing socio-economic inequalities and implementing outreach programmes for rural and indigenous populations. Programmes and practices that focus on the premise of health in all policies ${ }^{(61)}$ should be a priority to tackle issues of malnutrition in the country. The current study provides important information regarding the nutrition transition in Colombia.

\section{Acknowledgements}

Acknowledgements: The authors thank everyone who was involved and provided useful comments and recommendations, and who were part of D.C.P.'s dissertation committee including Christine Hoehner and Katie Stamatakis. Special thanks go to the Instituto Colombiano de Bienestar Familiar (ICBF) and PROFAMILIA, for providing support and allowing the use of the ENDS/ENSIN data sets to complete this study; particularly Daniel Ayala who provided invaluable support and input in data management and analysis. Financial support: Funding for this study was partially provided by an International Dissertation Scholarship from the Brown School to D.C.P. In addition, Project GUIA funded part of the research assistantship time of the lead author through the Centers for Disease Control and Prevention (Prevention Research Centers Program, contract U48/DP000060-01). The funders had no role in the design, analysis or writing of this article. Conflict of interest: The authors declare that they have no competing interests. Authorship: D.C.P. conceived of the study, prepared all the data sets, completed all the analyses and drafted the initial manuscript. R.C.B., L.F.G., L.I., D.H.-J. and A.K.S.K. participated in the writing and interpretation of results and revisions of the manuscript. All authors made substantial contributions to the manuscript and interpretations of results. All authors approved the final version and agreed to be accountable for all aspects of the work. Ethics of human subject participation: Institutional review board approval for the analyses conducted in this study was not deemed necessary since there were no personal identifiers linking the data to individuals.

\section{References}

1. Fotso J-C \& Kuate-Defo B (2006) Household and community socioeconomic influences on early childhood malnutrition in Africa. J Biosoc Sci 38, 289-313.

2. Menon P, Ruel MT \& Morris SS (2000) Socioeconomic Differentials in Child Stunting are Consistently Larger in Urban than in Rural Areas. Food and Nutrition Discussion Paper no. 97. Washington, DC: International Food Policy Research Institute.

3. Van de Poel E, Hosseinpoor AR, Speybroeck N et al. (2008) Socioeconomic inequality in malnutrition in developing countries. Bull World Health Organ 86, 282-291.

4. Petrou S \& Kupek E (2010) Poverty and childhood undernutrition in developing countries: a multi-national cohort study. Soc Sci Med 71, 1366-1373.

5. Bose K, Bisai S, Chakraborty J et al. (2008) Extreme levels of underweight and stunting among pre-adolescent children of low socioeconomic class from Madhyamgram and Barasat, West Bengal, India. Coll Antropol 32, 73-77.

6. Fotso J-C \& Kuate-Defo B (2005) Socioeconomic inequalities in early childhood malnutrition and morbidity: modification of the household-level effects by the community SES. Health Place 11, 205-225.

7. Monteiro CA, Hawkes C \& Caballero B (2010) The underweight/overweight paradox in developing societies: causes and policy implications. In Obesity Prevention: The Role of Brain and Society on Individual Behavior, pp. 463-469 [L Dube, A Bechara, A Dagher et al., editors]. London: Elsevier Inc.

8. McLaren L (2007) Socioeconomic status and obesity. Epidemiol Rev 29, 29-48.

9. Monteiro CA, Moura EC, Conde WL et al. (2004) Socioeconomic status and obesity in adult populations of developing countries: a review. Bull World Health Organ 82, 940-946.

10. Monteiro CA, Conde WL \& Popkin B (2007) Income-specific trends in obesity in Brazil: 1975-2003. Am J Public Health 97, 1808-1812.

11. Fernald LC, Gutierrez JP, Neufeld LM et al. (2004) High prevalence of obesity among the poor in Mexico. JAMA 291, 2544-2545.

12. Dinsa GD, Goryakin Y, Fumagalli E et al. (2012) Obesity and socioeconomic status in developing countries: a systematic review. Obes Rev 13, 1067-1079.

13. Arrizabalaga-Amarelo R \& Mendieta-Zerón H (2007) Obesity among parents and children from an indigenous rural community in Mexico. Sao Paulo Med J 125, 370-371.

14. Neufeld LM, Hernandez-Cordero S, Fernald LC et al. (2008) Overweight and obesity doubled over a 6-year period in young women living in poverty in Mexico. Obesity (Silver Spring) 16, 714-717.

15. Parra DC, Iannotti L, Gomez LF et al. (2015) The nutrition transition in Colombia over a decade: a novel household classification system of anthropometric measures. Arch Public Health 73, 12.

16. Garcia S, Sarmiento OL, Forde I et al. (2013) Socioeconomic inequalities in malnutrition among children and adolescents in Colombia: the role of individual-, householdand community-level characteristics. Public Health Nutr 16, 1703-1718.

17. Sarmiento OL, Ramirez A, Kutschbach BS et al. (2012) Nutrition in Colombian pregnant women. Public Health Nutr 15, 955-963.

18. Borda M (2007) The malnutrition paradox. Salud Uninorte Barranquilla (Col) 23, 276-291.

19. McDonald CM, Baylin A, Arsenault JE et al. (2009) Overweight is more prevalent than stunting and is associated with socioeconomic status, maternal obesity, and a snacking 
dietary pattern in school children from Bogotá, Colombia. J Nutr 139, 370-376.

20. Larrea C \& Freire W (2002) Social inequality and child malnutrition in four Andean countries. Rev Panam Salud Publica 11, 356-364.

21. Fall CH, Sachdev HS, Osmond C et al.; COHORTS investigators (2015) Association between maternal age at childbirth and child and adult outcomes in the offspring: a prospective study in five low-income and middle-income countries (COHORTS collaboration). Lancet Glob Health $\mathbf{3}$, e366-e377.

22. Crepinsek MK, Singh A, Bernstein LS et al. (2006) Dietary effects of universal-free school breakfast: findings from the evaluation of the school breakfast program pilot project. J Am Diet Assoc 106, 1796-1803.

23. Bernal R \& Camacho A (2010) La Importancia de los Programas para la Primera Infancia en Colombia. Bogota: Universidad de Los Andes, Centro de Estudios sobre Desarrollo Económico.

24. Isanaka S, Mora-Plazas M, Lopez-Arana S et al. (2007) Food insecurity is highly prevalent and predicts underweight but not overweight in adults and school children from Bogota, Colombia. J Nutr 137, 2747-2755.

25. Hackett M, Melgar-Quinonez H \& Alvarez MC (2009) Household food insecurity associated with stunting and underweight among preschool children in Antioquia, Colombia. Rev Panam Salud Publica 25, 506-510.

26. Dufour DL, Bender RL \& Reina JC (2015) Local trends in diet in urban Colombia, 1990-1995 to 2008: little evidence of a nutrition transition among low-income women. Am J Hum Biol 27, 106-115.

27. The World Bank (2017) Colombia - Encuesta Nacional de Demografía y Salud 2010. http://microdata.worldbank.org/ index.php/catalog/1361/study-description (accessed May 2018).

28. World Health Organization (2006) WHO Child Growth Standards: Length/Height-for-Age, Weight-for-Age, Weightfor-Length, Weight-for-Height and Body Mass Index-forAge: Methods and Development. Geneva: WHO.

29. Rutstein SO \& Johnson K (2004) The DHS Wealth Index. Calverton, MD: ORC Macro.

30. Alvarez MC, Estrada A, Montoya EC et al. (2006) Validation of a household food security scale in Antioquia, Colombia. Salud Publica Mex 48, 474-481.

31. Lorenzana PA \& Mercado C (2002) Measuring household food security in poor Venezuelan households. Public Health Nutr 5, 851-857.

32. Wehler CA, Scott RI \& Anderson JJ (1992) The community childhood identification project: a model of domestic hunger-demonstration project in Seattle, Washington. J Nutr Educ 24, Suppl, 29S-35S.

33. Zou KH, Detora LM, Haker SJ et al. (2009) Revisiting the p-value: a comparison of statistical evidence in clinical and legal medical decision making. Law Probab Risk 8, 159-170.

34. Coitinho DC, Sichieri R \& D'Aquino Benicio MH (2001) Obesity and weight change related to parity and breastfeeding among parous women in Brazil. Public Health Nutr 4, 865-870.

35. Mansour AA \& Ajeel NA (2009) Parity is associated with increased waist circumference and other anthropometric indices of obesity. Eat Weight Disord 14, e50-e55.

36. Huayanay-Espinoza CA, Quispe R, Poterico JA et al. (2017) Parity and overweight/obesity in Peruvian women. Prev Chronic Dis 14, E102.

37. Carlsen EM, Renault KM, Norgaard K et al. (2014) Newborn regional body composition is influenced by maternal obesity, gestational weight gain and the birthweight standard score. Acta Paediatr 103, 939-945.
38. Mitanchez D, Jacqueminet S, Nizard J et al. (2017) Effect of maternal obesity on birthweight and neonatal fat mass: a prospective clinical trial. PLoS One 12, e0181307.

39. Boissonnet C, Schargrodsky H, Pellegrini F et al. (2011) Educational inequalities in obesity, abdominal obesity, and metabolic syndrome in seven Latin American cities: the CARMELA Study. Eur J Cardiovasc Prev Rehabil 18, 550-556.

40. Traill B (2006) Trends Towards Overweight in Lower and Middle-Income Countries: Some Causes and Economic Policy Options. Rome: FAO.

41. Popkin BM (2006) Global nutrition dynamics: the world is shifting rapidly toward a diet linked with noncommunicable diseases. Am J Clin Nutr 84, 289-298.

42. Hofferth SL \& Curtin S (2005) Poverty, food programs, and childhood obesity. J Policy Anal Manage 24, 703-726.

43. Gregg EW, Cheng YJ, Narayan KM et al. (2007) The relative contributions of different levels of overweight and obesity to the increased prevalence of diabetes in the United States: 1976-2004. Prev Med 45, 348-352.

44. Barquera S, Peterson KE, Must A et al. (2007) Coexistence of maternal central adiposity and child stunting in Mexico. Int J Obes (Lond) 31, 601-607.

45. Fernald LC \& Neufeld LM (2007) Overweight with concurrent stunting in very young children from rural Mexico: prevalence and associated factors. Eur J Clin Nutr 61, 623-632.

46. Lee J, Houser RF, Must A et al. (2010) Disentangling nutritional factors and household characteristics related to child stunting and maternal overweight in Guatemala. Econ Hum Biol 8, 188-196.

47. Ramirez-Zea M, Kroker-Lobos MF, Close-Fernandez R et al. (2014) The double burden of malnutrition in indigenous and nonindigenous Guatemalan populations. Am J Clin Nutr 100, issue 6, 1644S-1651S.

48. Pratley RE (1998) Gene-environment interactions in the pathogenesis of type 2 diabetes mellitus: lessons learned from the Pima Indians. Proc Nutr Soc 57, 175-181.

49. Hawkes C (2002) Marketing activities of global soft drink and fast food companies in emerging markets: a review. In Globalization, Diets and Noncommunicable Diseases. Geneva: WHO.

50. Jones AD, Mundo-Rosas V, Cantoral A et al. (2017) Household food insecurity in Mexico is associated with the co-occurrence of overweight and anemia among women of reproductive age, but not female adolescents. Matern Child Nutr 13, e12396.

51. Deleuze Ntandou Bouzitou G, Fayomi B \& Delisle H (2005) Child malnutrition and maternal overweight in same households in poor urban areas of Benin. Sante $\mathbf{1 5}$, 263-270.

52. Food and Nutrition Organization of the United Nations (2004) Globalization of Food Systems in Developing Countries: Impact on Food Security and Nutrition. Rome: FAO.

53. Gulliford MC, Mahabir D \& Rocke B (2003) Food insecurity, food choices, and body mass index in adults: nutrition transition in Trinidad and Tobago. Int J Epidemiol 32, 508-516.

54. Rivera Castineira B, Currais Nunes L \& Rungo P (2009) The impact of conditional cash transfers on health status: the Brazilian Bolsa Familia Programme. Rev Esp Salud Publica 83, 85-97.

55. Adams EJ, Grummer-Strawn L \& Chavez G (2003) Food insecurity is associated with increased risk of obesity in California women. J Nutr 133, 1070-1074.

56. Oh SY \& Hong MJ (2003) Food insecurity is associated with dietary intake and body size of Korean children from lowincome families in urban areas. Eur J Clin Nutr 57, 1598-1604. 
57. Centers for Disease Control and Prevention (2003) Selfreported concern about food security associated with obesity. MMWR Morb Mortal Wkly Rep 52, 840-842.

58. Townsend MS, Peerson J, Love B et al. (2001) Food insecurity is positively related to overweight in women. $J$ Nutr 131, 1738-1745.

59. Leroy JL, Gadsden P, Rodriguez-Ramirez S et al. (2010) Cash and in-kind transfers in poor rural communities in Mexico increase household fruit, vegetable, and micronutrient consumption but also lead to excess energy consumption. J Nutr 140, 612-617.

60. Forde I, Chandola T, Garcia S et al. (2012) The impact of cash transfers to poor women in Colombia on BMI and obesity: prospective cohort study. Int J Obes (Lond) 36, 1209-1214.

61. Rudolph L, Caplan J, Ben-Moshe K et al. (2013) Health in All Policies: A Guide for State and Local Governments. Washington, DC and Oakland, CA: American Public Health Association and Public Health Institute. 